\title{
Partitioning of dioxins (PCDDs/Fs) in ambient air at urban residential locations
}

\author{
Md. M. Rahman · Z.-H. Shon • C.-J. Ma • \\ R. J. C. Brown · S. K. Pandey - C. G. Park • \\ I. S. Bae $\cdot$ J. R. Sohn $\cdot$ H.-O. Yoon $\cdot$ K.-H. Kim
}

Received: 11 December 2012/Revised: 26 April 2013/Accepted: 8 October 2013/Published online: 30 October 2013

(C) Islamic Azad University (IAU) 2013

\begin{abstract}
In this work, 17-polychlorinated dibenzo- $p$ dioxin/furan (PCDD/Fs) isomers were measured in ambient air at four urban sites in Seoul, Korea (from February to June 2009). The concentrations of their summed values $(\Sigma \mathrm{PCDD} / \mathrm{Fs})$ across all four sites ranged from 1,947 (271 $\mathrm{WHO}_{05}$ TEQ) (Jong Ro) to 2,600 (349 $\mathrm{WHO}_{05} \mathrm{TEQ}$ ) fg/ $\mathrm{m}^{3}$ (Yang Jae) with a mean of 2,125 $( \pm 317) \mathrm{fg} / \mathrm{m}^{3}(292$ $\mathrm{WHO}_{05}$ TEQ $\mathrm{fg} / \mathrm{m}^{3}$ ). The sum values for the two isomer groups of $\Sigma$ PCDD and $\Sigma$ PCDF were $527\left(30 \mathrm{WHO}_{05} \mathrm{TEQ}\right)$ and 1,598 (263 $\left.\mathrm{WHO}_{05} \mathrm{TEQ}\right) \mathrm{fg} / \mathrm{m}^{3}$, respectively. The concentration profile of individual species was dominated by the 2,3,4,7,8-PeCDF isomer, which contributed approximately $36 \%$ of the $\Sigma \mathrm{PCDD} / \mathrm{Fs}$ value. The observed temporal trends in $\mathrm{PCDD} / \mathrm{F}$ concentrations were characterized by relative enhancement in the winter and spring. The relative contribution of different sources, when assessed by principal component analysis, is explained by
\end{abstract}

Electronic supplementary material The online version of this article (doi:10.1007/s13762-013-0389-7) contains supplementary material, which is available to authorized users.

Md. M. Rahman · K.-H. Kim ( $\square)$

Department of Environment and Energy, Sejong University, Seoul 143-747, Republic of Korea

e-mail: khkim@sejong.ac.kr

Z.-H. Shon

Department of Environmental Engineering, Dong-Eui

University, Busan 614-714, Republic of Korea

C.-J. Ma

Department of Environmental Science, Fukuoka Women's University, Fukuoka, Japan

R. J. C. Brown

Analytical Science Division, National Physical Laboratory,

Hampton Rd, Teddington TW11 0LW, UK the dominance of vehicular emissions along with coal (or gas) burning as the key source of ambient PCDD/Fs in the residential areas studied.

Keywords PCDD/Fs - Gas/particle partitioning · Residential area $\cdot$ Seasonal variation

\section{Introduction}

Simply termed 'dioxins,' polychlorinated dibenzo- $p$-dioxins (PCDDs) and polychlorinated dibenzofurans (PCDFs) are observed in virtually all types of environmental matrices such as air, soil, and water (Tysklind et al. 1993). The molecular structure of PCDDs comprises two benzene rings connected by two oxygen atom bridges, whereas that of PCDFs consists of two benzene rings joined by a carbon bond and an oxygen bridge. Although there are $210 \mathrm{PCDD} / \mathrm{F}$ congeners with similar structures, their toxicity varies greatly according to the degree and position of the chlorine substitution (Kutz et al. 1990).

\footnotetext{
S. K. Pandey

Department of Botany, Guru Ghasidas Central University, Bilaspur, CG 495 009, India

C. G. Park · I. S. Bae

Seoul Metropolitan Institute of Public Health and Environment, Seoul 137-734, Republic of Korea

J. R. Sohn

Department of Environmental Health, Korea University, Seoul 136-703, Republic of Korea

H.-O. Yoon

Korea Basic Science Institute, Seoul Center, Anamdong, Seoul 136-713, Republic of Korea
} 
PCDD/Fs in the atmosphere may be present in the vapor phase or bound to particulate matter-depending on their sources and vapor pressure. The fate of PCDD/Fs in the air is hence governed primarily by their distribution between the gas and particulate phases. Transformation of these compounds in the atmosphere can occur through photolysis and reactions with the hydroxyl radical $(\mathrm{OH})$, nitrate $\left(\mathrm{NO}_{3}\right)$, and ozone $\left(\mathrm{O}_{3}\right)$. The reaction with $\mathrm{OH}$ is known to be the predominant oxidation process (Atkinson 1996; Kim et al. 2013). The atmospheric lifetimes of PCDD/Fs range from a few days to several weeks (see Table $1 \mathrm{~S}$ ). They may also undergo various degradation processes in the atmosphere (Kim et al. 2001a, b). Among the total 210 PCDD/Fs, a total of seventeen 2,3,7,8 substituted congeners are known to be toxic to many laboratory animals (Kutz et al. 1990) and toxic to human via exposure pathways such as inhalation, dermal contact, and ingestion (Jin et al. 1995; de Wit 2002; Fiedler 2003). In most cases they occur as a result of manmade activities such as waste incineration, automotive emissions, chemical production processes, and from steel works. The relatively long lifetimes of dioxins in the atmosphere allows for their transport across long distances (Dyke and Stratford 2002). During atmospheric transportation, different homologue groups of PCDD/Fs (in gas and/ or liquid phase) can be transferred to the earth's surface (Lohmann and Jones 1998). As 2,3,7,8 substituted congeners exhibit the tendency to bioaccumulate (ATSDR 1998), they are easily transferred from organisms to human bodies via food chain (Bocio and Domingo 2005, Gras and Muller 2004).

For this reason, a better knowledge of the factors affecting dioxin levels in ambient air can offer valuable insights into their sources and environmental behavior and may aid in assessing human exposure, current emissions levels, and the effectiveness of abatement strategies. Because the world's largest consumption of coal occurs in the northeast of Asia, an understanding of the atmospheric presence of these compounds in this region is particularly important (Bao and Sakamoto 2009; Huang et al. 2009; Matsumoto et al. 2009; Tang et al. 2009) .

This work was carried out to assess the distributions of dioxins in ambient air at four different locations in Seoul, Korea. As is the case of many large metropolitan cities in the world, Seoul is a rapidly growing urban area. In the course of this study, the dioxin concentrations were monitored at four urban sites in Seoul during the period of February to June 2009. The datasets were examined at various spatio-temporal scales to deconvolute the basic factors and processes that are likely to exert the greatest influences on their concentrations and distribution. The gas to particle phase partitioning of PCDD/Fs at the four sites was also estimated using modeling.

\section{Materials and methods}

Site characteristics

As the capital of Korea, Seoul is one of the biggest megacities in Northeast Asia, with a total area of $605 \mathrm{~km}^{2}$, and about 10 million inhabitants (Seoul Metropolitan Government 2010). With average altitude of $86 \mathrm{~m}$, the average monthly temperature and precipitation in Seoul are about $11.5^{\circ} \mathrm{C}$ and $105 \mathrm{~mm}$, respectively (Climatemap 2013). In this investigation, concentrations of the 17 most harmful PCDD/F congeners were measured at four sampling sites each of which is located on the rooftop of the respective local district office (3-4 story building: Fig. 1). These sites were selected to represent four different residential locations across the city of Seoul: Jong Ro (N), Gwang Jin (E), Yang Jae (S), and Gang Seo (W). In light of their geographical locations within Seoul, the sites have been abbreviated with the compass directions of $\mathrm{N}$ (north), $\mathrm{E}$ (east), S (south), and W (west), respectively. The GPS locations of these sampling sites are $\mathrm{N}\left(127^{\circ} 00.18^{\prime}\right.$, $\left.37^{\circ} 34.19^{\prime}\right)$, E $\left(127^{\circ} 05.44^{\prime}, 37^{\circ} 32.40^{\prime}\right)$, S $\left(127^{\circ} 01.55^{\prime}\right.$, $\left.37^{\circ} 27.51^{\prime}\right)$, and $\mathrm{W}\left(126^{\circ} 50.18^{\prime}, 37^{\circ} 32.11^{\prime}\right)$. Although these 4 sites may be classified as mainly residential areas, they are expected to be affected differently by anthropogenic processes. For example, site $\mathrm{E}$ is inside a large water purification facility with gross area of $13,732 \mathrm{~m}^{2}$. Site $\mathrm{W}$ is situated near a road in the proximity of a long-standing waste disposal site. Sites $\mathrm{N}$ and $\mathrm{S}$ have no specific point source(s) associated with them, although they are likely to be affected by local traffic activities.

\section{Sampling and chemical analysis for dioxins}

Air samples were collected from the four sites over three consecutive days in each month from February to June 2009 (23-25 February, 9-11 March, 6-8 April, 11-13 May, and 6-8 June). The collection of each sample started at $3 \mathrm{pm}$ and ran for $24 \mathrm{~h}$ so that the total sampling duration per month was about $72 \mathrm{~h}$. For dioxin analysis, both particle and gas phase samples were collected using a high volume sampler (HV-1000F, SIBATA, Japan). The total sampled volume of air was approximately $1,150 \mathrm{~m}^{3}$ per sampling day using an airflow rate of $800 \mathrm{~L} \mathrm{~min}^{-1}$. Quartz filters were used for the collection of particle phase dioxins, and polyurethane foam (PUF) was used for gas dioxins. Prior to sampling, the quartz filter was baked at $600{ }^{\circ} \mathrm{C}$ for $5 \mathrm{~h}$. In case of PUF, precleaning was made with acetone in soxhlet for $16 \mathrm{~h}$ and stored in aluminum foil after final cleaning with normal hexane. Then, samples were collected using a glass cartridge sampler, which consisted of a 5-cm PUF plug, a 3-cm XAD-2 resin cartridge, and a $2-\mathrm{cm}$ 


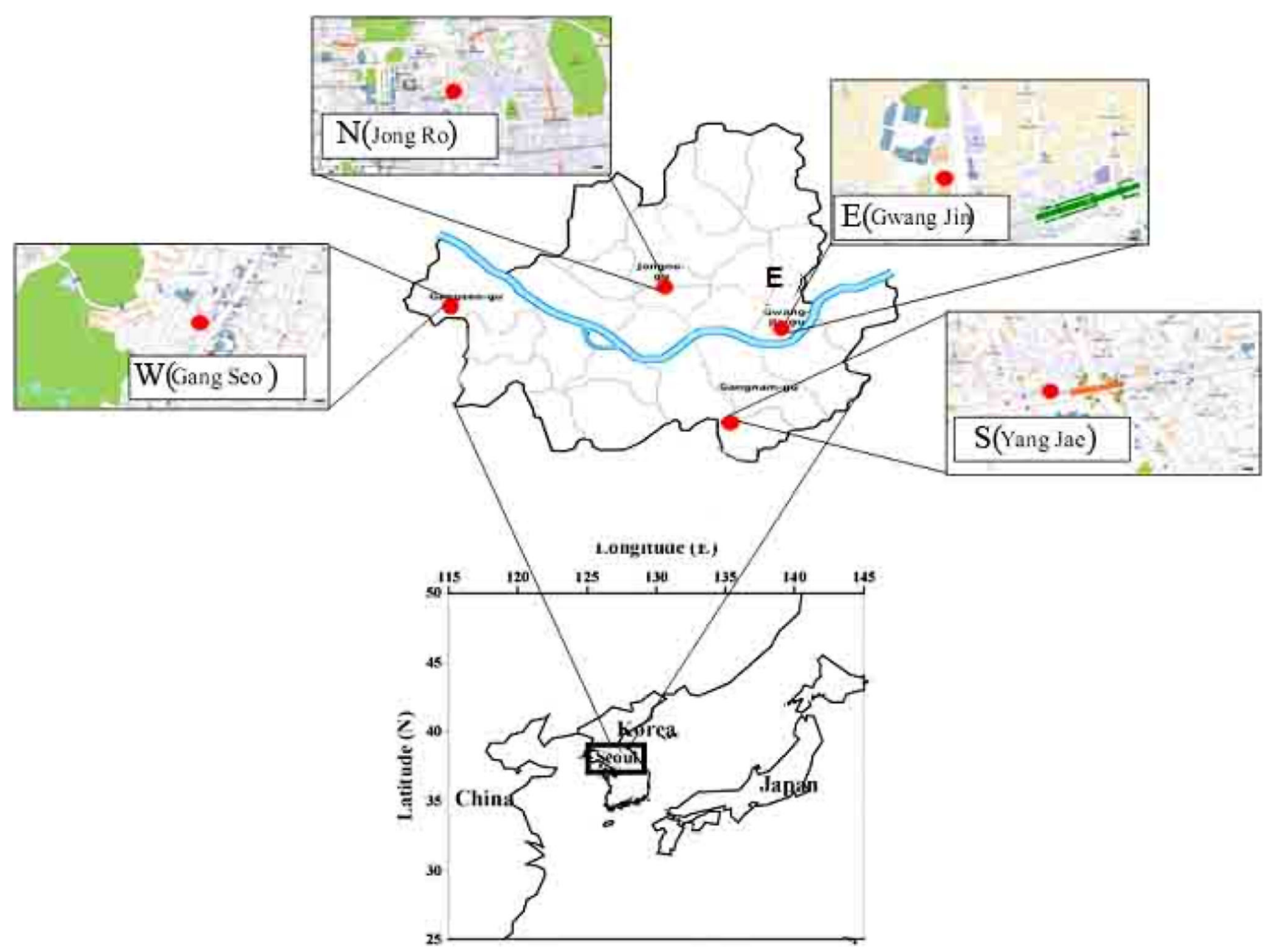

Fig. 1 Geographical location of the four study sites for the measurements of ambient PCDD/Fs level in Seoul, Korea

PUF plug. The concentrations of dioxins in this study were derived as the sum of both gas and particulate fractions.

The collection and analysis of PCDDs/PCDFs samples were performed using US EPA method 1613 (US EPA 1994). For the analysis of vapor-phase PCDD/Fs, PUF samples were transferred to a Soxhlet extraction receptacle, spiked with $10 \mu \mathrm{L}$ of a mixture of ${ }^{13} \mathrm{C}$ labeled PCDD/F compounds (in the concentration range of 100-200 ng/mL) and extracted with toluene for $16 \mathrm{~h}$. Samples were subsequently cleaned up using silica gel $(15 \mathrm{~mm} \mathrm{ID} \times 30 \mathrm{~cm}$ column) and acid alumina (10 $\mathrm{mm} \mathrm{ID} \times 30 \mathrm{~cm}$ column). Pretreatment of samples was made following the analytical procedure of Oh et al. (2001).

All $\left[{ }^{13} \mathrm{C} 12\right]$-labeled internal and performance standards, and the calibration solution, were purchased from Wellington Laboratories (Ont., Canada). As shown in Table 1S, a total of 17 PCDDs/PCDFs were analyzed by high-resolution gas chromatography/high-resolution mass spectrometry (Thermo Scientific Trace GC Ultra/High Resolution Magnetic Sector MS; Germany) using a SP-2331 column (60 m, $0.32 \mathrm{~mm}$ i.d. $0.25 \mu \mathrm{m}$ film thickness). During analysis, the carrier gas (helium) was supplied at flow rate $1.3 \mathrm{~mL} / \mathrm{min}$ with an injector temperature of $260{ }^{\circ} \mathrm{C}$. The temperature of oven was set initially at $100{ }^{\circ} \mathrm{C}(1 \mathrm{~min})$ and increased at ramp rate of $10{ }^{\circ} \mathrm{C} / \mathrm{min}$ to a final temperature of $230{ }^{\circ} \mathrm{C}$ (1 min). Samples were injected into the injection port in splitless mode. The GC-MS was operated in electron impact mode $(+30 \mathrm{eV})$ above a resolution of 10,000 . Detection was made using selective ion monitoring (SIM) mode, and the ion source temperature was set at $260{ }^{\circ} \mathrm{C}$. Before analyzing real samples, a five-point calibration was performed using standard solutions of PCDDs/PCDFs in the range $0.5-2,000 \mathrm{ng} /$ $\mathrm{mL}$. The method detection limit (MDL) of our system, when tested by injection of $0.5-5 \mathrm{pg}$ of standards into the GC-MS, generally ranged from 0.058 (for TCDF) to $0.663 \mathrm{pg}$ (for OCDF), as shown in Table $2 \mathrm{~S}$. For a total sampling volume of $1,152 \mathrm{~m}^{3}$ (over $24 \mathrm{~h}$ ), those MDL values correspond to 0.05 and $0.663 \mathrm{fg} / \mathrm{m}^{3}$, respectively. The reproducibility of analysis, if expressed in terms of relative standard error (RSE), ranged from 0.58 (for OCDF) to $2.29 \%$ (for $\mathrm{HpCDF}$ ). The toxic 2,3,7,8-substituted PCDD/Fs as well as tetra- to octa-chlorinated homologues were quantified at 
isotope ratios within $\pm 15 \%$ of the theoretical values and signal-noise ratio of $\geq 2.5$. Recoveries of ${ }^{13} \mathrm{C}_{12}$-lebelled $\mathrm{PCDD} / \mathrm{Fs}$ internal standards in environmental samples ranged from 50 to $120 \%$ which satisfied the criterion suggested by the EPA method 1613 .

Models applied for gas/particle partitioning of PCDD/Fs

The simplest approximation for describing the partitioning of semi-volatile organic compounds between the gas and particle phases is to consider physical adsorption onto the particle surface. The most common adsorption model is the Junge-Pankow model based on linear Langmuir isotherm (Junge 1977; Pankow 1987). It was assumed that the physical adsorption onto the particle surface is the main mechanism that governs the atmospheric distribution of chemical compound (i.e., equivalence on all adsorption sites of the surface, no horizontal interactions among adsorbed molecules, and same heat of adsorption for all molecules to any site) (Seinfeld and Pandis 2006):

$\phi=C_{\mathrm{p}} /\left(C_{\mathrm{g}}+C_{\mathrm{p}}\right)=c \theta\left(P_{\mathrm{L}}^{0}+c \theta\right)$

where $C_{\mathrm{p}}$ and $C_{\mathrm{g}}$ are the particulate and gas phase concentration of semi-volatile organic compounds, respectively, $\phi$ is the fraction of semi-volatile organic compound adsorbed to particles, $P_{\mathrm{L}}^{0}$ the subcooled vapor pressure of the compound at ambient temperature $\mathrm{T}(\mathrm{K}), \theta$ $\left(\mathrm{cm}^{2} \mathrm{~cm}^{-3}\right)$ is the surface area concentration of the particle, and $c$ is a parameter that depends on the heat of condensation of the compounds and the surface properties. A value of $17.2 \mathrm{~Pa} \mathrm{~cm}$ for $c$, employed by Junge for high molecular weight organics, was used in this study. A surface area concentration $\theta$ of $1.1 \times 10^{-5} \mathrm{~cm}^{2} \mathrm{~cm}^{-3}$ for urban conditions was used. The Junge-Pankow model has limitations due the uncertainties in the parameters $c$ and $\theta$. For comparison purposes, three methods were employed to calculate $P_{\mathrm{L}}^{0}$. First, the vapor pressures for PCDD/Fs were estimated from the following equation (Paasivirta et al. 1999; Yamasaki et al. 1982):

$\log P_{\mathrm{L}}^{0}=m_{\mathrm{L}} / T+b_{\mathrm{L}}$

where $m_{\mathrm{L}}$ and $b_{\mathrm{L}}$ are congener-dependent constants.

The second calculation used the relation between the vapor pressure of the crystalline solid $\left(P_{\mathrm{s}}^{0}\right)$ and $P_{\mathrm{L}}^{0}$ (Rordorf 1989; Mackay et al. 1982):

$\operatorname{Ln}\left(P_{\mathrm{s}}^{0} / P_{\mathrm{L}}^{0}\right)=6.8\left(T_{\mathrm{m}}-T\right) / T$

where $T_{\mathrm{m}}$ is the melting temperature. However, it is recognized that there is some uncertainty in the conversion factor of 6.8 for PCDD/Fs (Hinckley et al. 1990). Thirdly, Eitzer and Hites (1988) used an empirical relationship between the retention time index (RTI) for PCDD/Fs on a nonpolar GC-column and their vapor pressure $\left(P_{\mathrm{L}}^{0}\right)$ thus:

$$
\begin{aligned}
\log P_{\mathrm{L}}^{0}= & -1.34(\mathrm{RTI}) / T+1.67 \times 10^{-3}(\mathrm{RTI})-1320 / T \\
& +8.087
\end{aligned}
$$

The RTI was taken from Donelly et al. (1987) and Hale et al. (1985). In this study, gas/particle partitioning coefficients, $K_{\mathrm{p}}\left(\mathrm{m}^{3} \mathrm{\mu g}^{-1}\right)$ were also estimated using following equations. Measurements show that there is a high correlation between $K_{\mathrm{p}}$ and $P_{\mathrm{L}}^{0}$ (Pankow 1991):

$\log K_{\mathrm{p}}=m \log P_{\mathrm{L}}^{0}+b$

The $K_{\mathrm{p}}$ can also be calculated using octanol/air partition coefficient $\left(K_{\mathrm{oa}}\right)$ (Harner and Bidleman 1998):

$\log K_{\mathrm{p}}=\log K_{0 \mathrm{a}}+\log f_{\text {om }}-11.91$

where $f_{\text {om }}$ is the organic matter fraction and was calculated from the ratio of organic carbon to total suspended particulate concentrations measured during the study. The term $K_{\mathrm{oa}}$ was calculated from the octanol/water partition coefficient, $K_{\text {ow }}$, and Henry's law constant, $\mathrm{H}$ :

$K_{\text {oa }}=K_{\text {ow }} \mathrm{RT} / H$

The values of $\mathrm{K}_{\mathrm{ow}}$ and $\mathrm{H}$ were adopted from Govers and Krop (1998). The term $\mathrm{K}_{\mathrm{oa}}$ was also calculated using RTI (Harner et al. 2000) and temperature (Harner and Bidleman 1996):

$\log K_{\mathrm{oa}}=m^{\prime}(\mathrm{RTI})+b^{\prime}$

$\log K_{\text {oa }}=m^{\prime \prime} / T+b^{\prime \prime}$

Li et al. (2008) has pointed out that the $K_{\text {oa }}$ absorption model might actually work better than the Junge-Pankow adsorption model due to underestimation of the particulate fractions of PCDD/Fs by the latter. They found that the $\mathrm{K}_{\mathrm{oa}}$ model fitted well with the measurement results. In this way, the sensitivity of $\phi$ to the different models applied for the calculation of $P_{\mathrm{L}}^{0}$ was assessed as part of this study.

\section{Results and discussion}

The brief overview of dioxins at the four study sites

The concentrations of $17 \mathrm{PCDD} / \mathrm{Fs}$ congeners measured at the four monitoring sites (N, E, S and W) are illustrated in Fig. 2. In this study, together with the expression of results in mass concentration units of $\mathrm{fg} / \mathrm{m}^{3}$, the latest toxic equivalency factors (TEQ) published by the World Health Organization in 2005 were used to convert these mass concentrations into $\mathrm{WHO}_{05}$ I-TEQ $\mathrm{fg} / \mathrm{m}^{3}$. The concentrations of each compound were strongly correlated but with 


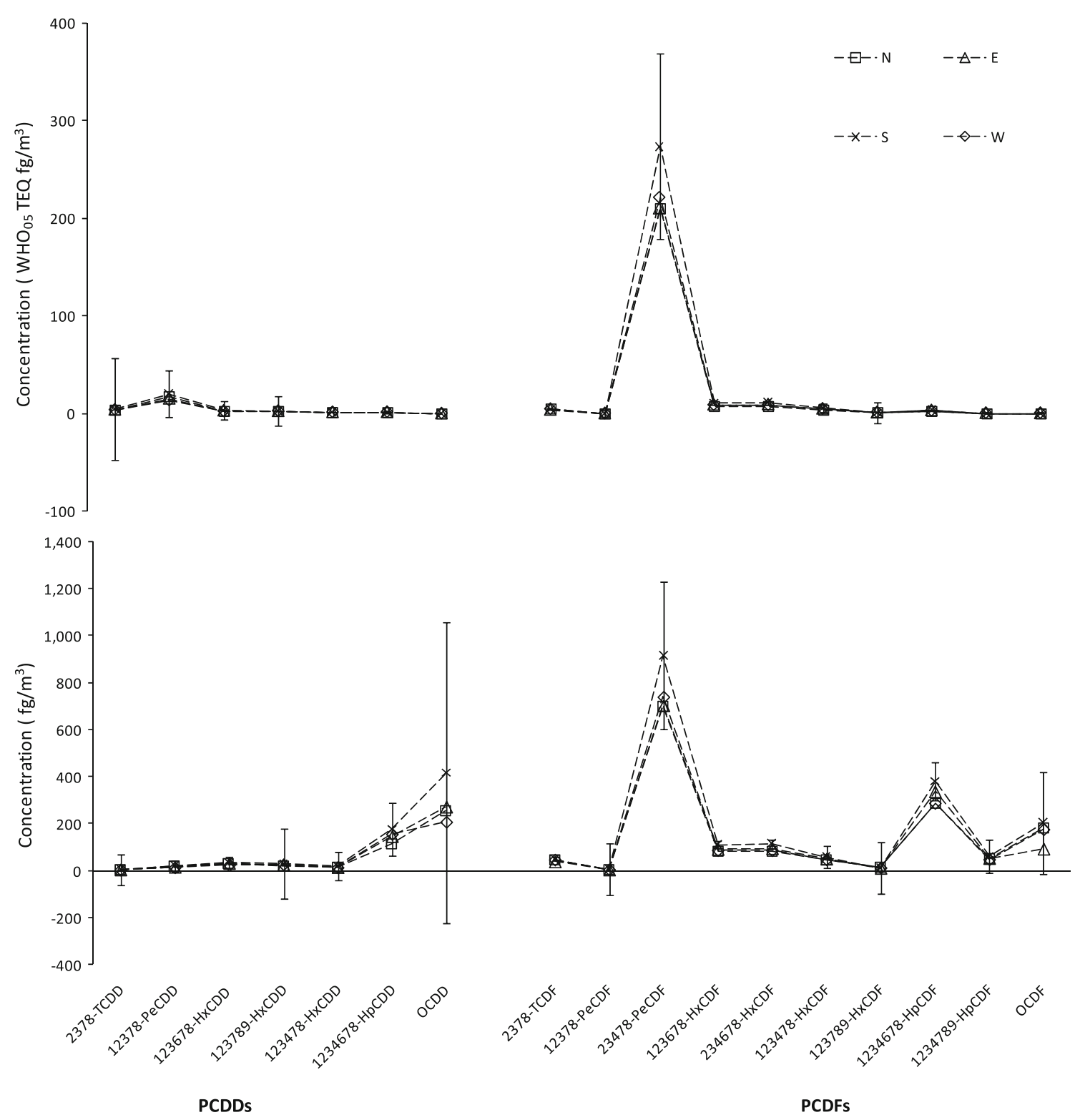

Fig. 2 Comparison of the mean concentration $\left(\mathrm{fg} / \mathrm{m}^{3}\right)$ and toxicity $\left(\mathrm{WHO}_{05}\right.$ TEQ $\left.\mathrm{fg} / \mathrm{m}^{3}\right)$ units of each PCDD and PCDF considered in this study at the four sites: N, E, S, and W, between February and June 2009. Error bars indicate standard deviation

some variations between sites (Fig. 2). Of all the species measured during the study, 23478-PeCDF recorded the highest concentration of $914\left(229 \mathrm{WHO}_{05} \mathrm{TEQ}\right) \mathrm{fg} / \mathrm{m}^{3}$ at $\mathrm{S}$, while 2378-TCDD had the lowest concentration of 3.7 (3.7 $\left.\mathrm{WHO}_{05} \mathrm{TEQ}\right) \mathrm{fg} / \mathrm{m}^{3}$ at E. It should be mentioned that concentrations of 23478-PeCDF were below $200 \mathrm{fg} / \mathrm{m}^{3}$ in many other studies conducted in both residential and industrial sites. The overall PCDD/Fs data obtained in this study $\left(2,125 \mathrm{fg} / \mathrm{m}^{3}\right)$ can be compared with the value of about 870 (39 $\mathrm{WHO}_{05}$ TEQ) $\mathrm{fg} / \mathrm{m}^{3}$ measured previously in residential areas in Seoul in 1998-99 (Kim et al. 2001a, b). In contrast, in a survey conducted more recently (2002-2009) in Seoul, an average of $3,300 \mathrm{fg} / \mathrm{m}^{3}$ was reported (Kim et. al. 2010). If taken together with the data of Kim et al. (2010), our results suggest a trend of decreasing PCDD/Fs concentrations in Seoul over the past decade. It should also be noted that the concentration observed in this study is about $1,000 \mathrm{fg} / \mathrm{m}^{3}$ lower than those measured in both industrial and residential areas in Sao Paulo (De Assuncao et al. 2005) and three times lower than the values obtained from a industrial waste incineration (IWI) site in Korea (Kim et al. 2005).

As seen in Fig. 3, the relative concentrations of $\Sigma \mathrm{PCDD} / \mathrm{Fs}$ were highly consistent across all sites. The mean concentrations of $\Sigma \mathrm{PCDD} / \mathrm{Fs}$ at all sites (N, S, E and W) were about $2,125 \mathrm{fg} / \mathrm{m}^{3}$ (Table 1). As all the target compounds belong to either one of the two groups (PCDDs or PCDFs), the concentrations of individual components 
Fig. 3 Comparison of the mean concentrations of $\sum P C D D$, $\sum \mathrm{PCDF}$ and $\sum \mathrm{PCDD} / \mathrm{Fs}$ across the 4 urban sites in Seoul

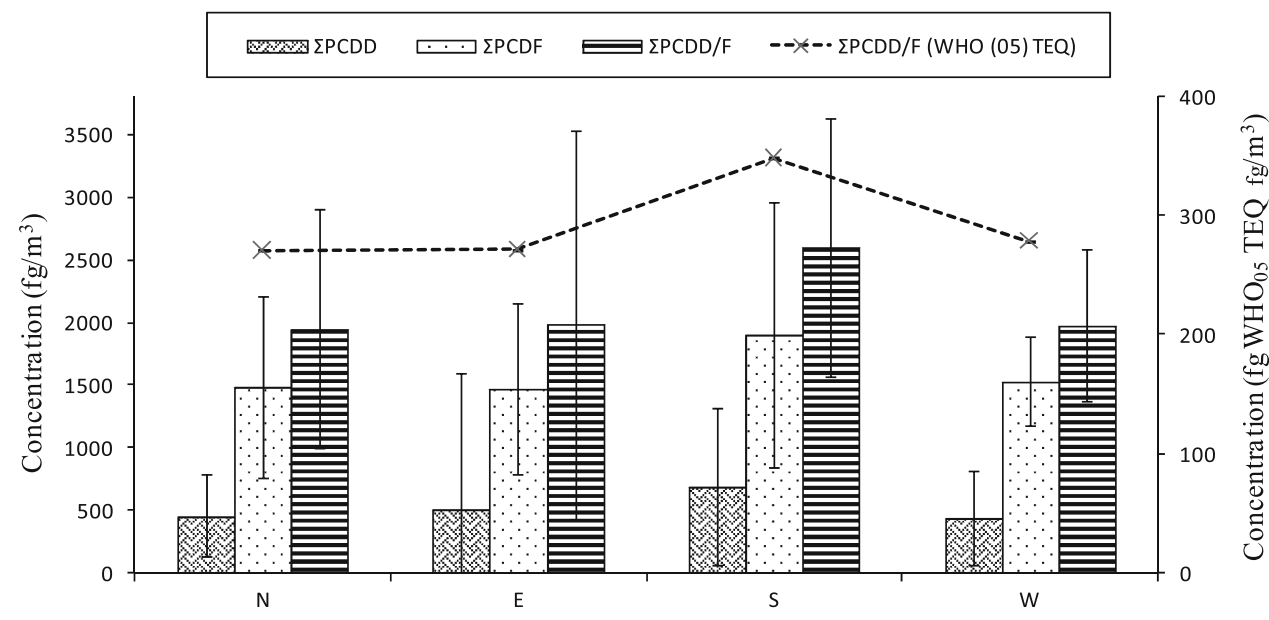

can be compared both on an individual basis and by the sum value for each grouping. In this respect, the mean concentration of $\Sigma$ PCDF (1,598 (263 $\left.\mathrm{WHO}_{05} \mathrm{TEQ}\right) \mathrm{fg} / \mathrm{m}^{3}$ ) is 3 times larger than that of the $\Sigma$ PCDD (527 $\left(29 \mathrm{WHO}_{05}\right.$ TEQ) $\mathrm{fg} / \mathrm{m}^{3}$ ). In addition, of the PCDDs, OCDD recorded the highest $\mathrm{fg} / \mathrm{m}^{3}$ concentration of 207-415 (0.06-0.12 $\mathrm{WHO}_{05}$ TEQ), while 2378-TCDD showed the lowest at 3.7-4.7 (3.7-4.7 $\mathrm{WHO}_{05}$ TEQ) (Fig. 2). In contrast, of the PCDFs, 23478-PeCDF showed the highest $\mathrm{fg} / \mathrm{m}^{3}$ concentration of 699-914 (210-274 $\mathrm{WHO}_{05}$ TEQ), while 12378-PeCDF showed the lowest at 3.7-5.7 (0.11-0.17 $\mathrm{WHO}_{05}$ TEQ). The observed maximum and minimum relationships of these PCDF components were consistent across all 4 sites, as shown in Fig. 2.

Spatial variations in dioxin concentrations between the 4 urban sites

As measurements were made at multiple locations within the same city, these data can be used to evaluate spatial distribution patterns. To do this, mean PCDDs/Fs concentrations were compared across the four sites considered (Fig. 2). Site $\mathrm{S}$ showed the highest mean value of 2,599 (349 $\mathrm{WHO}_{05}$ TEQ), followed by 1,979 (271 $\left.\mathrm{WHO}_{05} \mathrm{TEQ}\right)$ (E), 1,974 (279 $\mathrm{WHO}_{05}$ TEQ) (W), and 1,947 (271 $\mathrm{WHO}_{05}$ TEQ) (N) $\mathrm{fg} / \mathrm{m}^{3}$. As shown in Fig. 2, the relative enhancement of PCDF concentrations over those of PCDDs seems to be consistent across sites. The summed concentrations of the separate PCDD and PCDF groups consistently showed the highest values at $\mathrm{S}$ with $697\left(35 \mathrm{WHO}_{05}\right.$ TEQ) and 1,902 (313 $\left.\mathrm{WHO}_{05} \mathrm{TEQ}\right) \mathrm{fg} / \mathrm{m}^{3}$, respectively.

To allow a comparison of the relative concentration profiles across different sites, the concentration data from each site have been normalized to the respective mean values (Fig. 1S in Supplementary Material). The results of this normalization confirm the systematic dominance of site $\mathrm{E}$ for most PCDD/F compounds. Among individual species, the highest mean values $\left(\mathrm{fg} / \mathrm{m}^{3}\right)$ were seen consistently from 23478-PeCDF from all 4 sites yielding such values as $699(\mathrm{~N}) \sim 914(\mathrm{E}) \mathrm{fg} / \mathrm{m}^{3}$. The lowest mean values $\left(\mathrm{fg} / \mathrm{m}^{3}\right)$ were on the other hand seen consistently from 2378-TCDD with concentrations such as $3.7(\mathrm{~S}) \sim 4.7$ (E). As was the case for PCDDs, the PCDF species exhibited highly consistent patterns across all four sites (fg/ $\mathrm{m}^{3}$ ). The maximum mean values of PCDF were found for 23478-PeCDF (914 (E) $699(\mathrm{~S}) \mathrm{fg} / \mathrm{m}^{3}$ ), while minimum values were found for 12378 -PeCDF $(4.3(\mathrm{~N}) \sim 5.7$ (E) fg/ $\left.\mathrm{m}^{3}\right)$. The OCDD isomers showed the highest variability: 415 (E) 206 (S) fg/m $\mathrm{m}^{3}$, followed by 12378-PeCDD, 123678-HxCDF, and 123678-HxCDD. In contrast, OCDF concentrations were found in a very narrow range of normalized concentrations $(0.9(\mathrm{~W}) \sim 1.12(\mathrm{E}))$. Similar trends were also found for 2,3,7,8-TCDD and 2378-TCDF. One of the most important conclusions from Fig. 3 is that the dioxin concentrations at each site are highly correlated, except site $\mathrm{S}$. As a result, the concentration ratios for given dioxin pairs stay relatively constant even as absolute concentrations change. This may reflect the fact that the origin of dioxin emissions generally share the same type of processes, i.e., burning, therefore producing similar dioxin concentration profiles. A similar effect is also observed for $\mathrm{PAH}$ concentrations in ambient air. Moreover, subtle variations in these concentration profiles can be a useful tool for source apportionment. The correlation observed between dioxin congeners also means that there is likely to be a strong correlation between the concentration expressed in mass $\left(\mathrm{fg} / \mathrm{m}^{3}\right)$ and toxicity equivalent $\left(\mathrm{WHO}_{05}\right.$ TEQ $\mathrm{fg} / \mathrm{m}^{3}$ ) units. This would not be the case if the relative concentrations of dioxin congeners showed significant variations.

Spatial concentration differences are usually related to the relative strength of local anthropogenic emissions (Table 1). The concentration of $\Sigma$ PCDD/Fs measured in our study $\left(2,125 \mathrm{fg} / \mathrm{m}^{3}\right)$ is approximately similar to those of a residential site in Lancaster, UK (1,945 and 1,812 fg/ $\mathrm{m}^{3}$ ) and more than double than those of a residential area of 


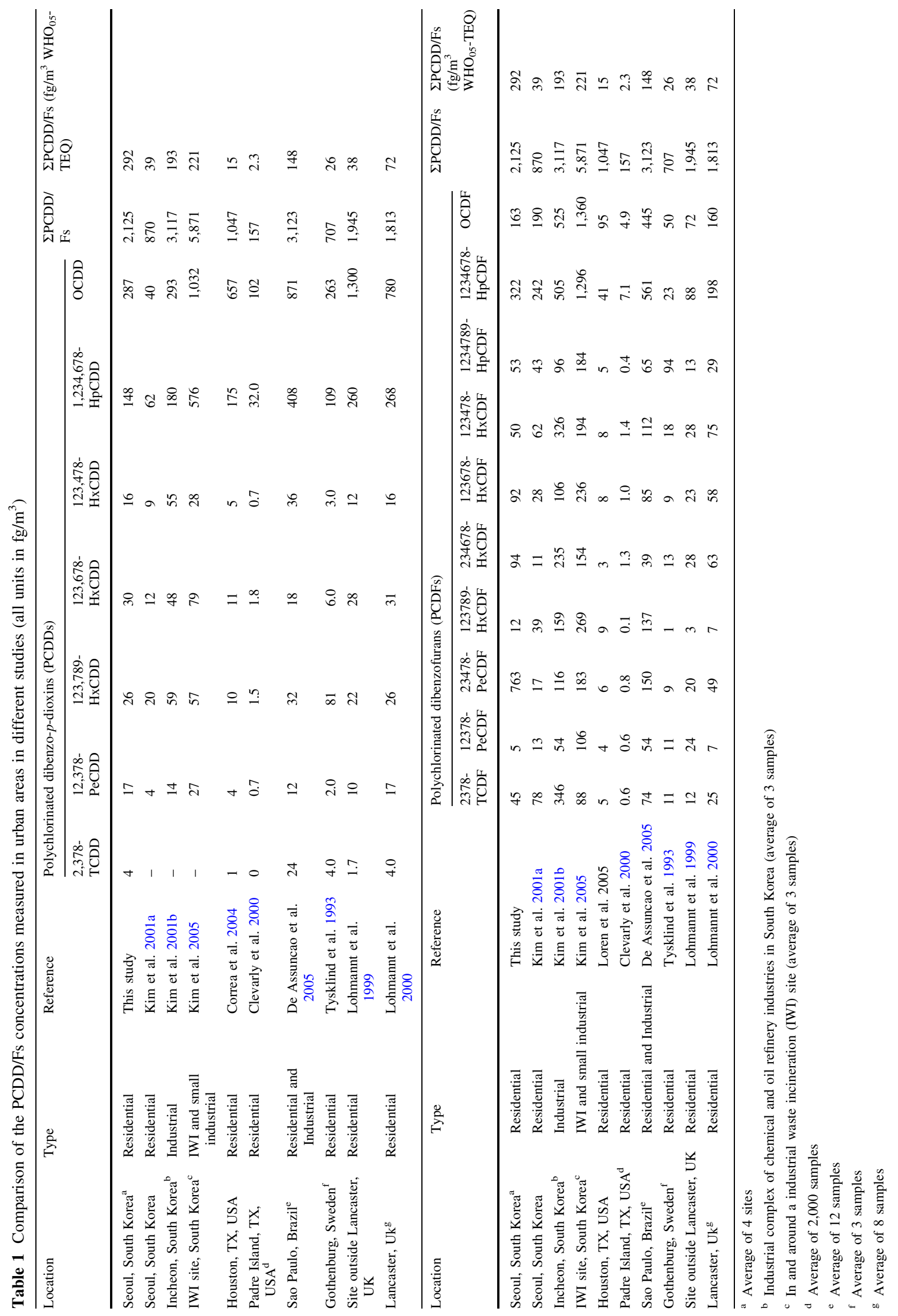


Houston, TX, USA $\left(1,047 \mathrm{fg} / \mathrm{m}^{3}\right)$. Similarly, $\Sigma$ PCDD/Fs concentrations at residential sites in Gothenburg, Sweden in 1993 were much lower at $707 \mathrm{fg} / \mathrm{m}^{3}$. Moreover, the concentrations of $\Sigma \mathrm{PCDD} / \mathrm{Fs}$ found in an area with few local sources like Padre Island, TX, USA were significantly lower at about $157 \mathrm{fg} / \mathrm{m}^{3}$.

Unlike the results observed from relatively unpolluted sites, previous results from strong local sources (like industrial and waste incineration facilities) showed very high $\Sigma \mathrm{PCDD} / \mathrm{Fs}$ concentrations. For example, in Inchon, South Korea, $\Sigma \mathrm{PCDD} / \mathrm{Fs}$ concentrations at an industrial site were as high as $3,117 \mathrm{fg} / \mathrm{m}^{3}$. In another study (in 2005) conducted on a remote site in Korea influenced by small-scale industrial waste incineration, the $\Sigma \mathrm{PCDD} / \mathrm{Fs}$ concentration was $5,871 \mathrm{fg} / \mathrm{m}^{3}$. Oh et. al. (2006) investigated dioxins near municipal solid waste incinerators in Bucheon, Korea. According to their analysis, $\Sigma \mathrm{PCDD} / \mathrm{F}$ values fell in the range of $13,390-75,160 \mathrm{fg} / \mathrm{m}^{3}$. Moreover, from a site influenced heavily by industry and traffic in Sao Paulo, Brazil, the $\Sigma \mathrm{PCDD} / \mathrm{Fs}$ concentration was measured at $3,123 \mathrm{fg} / \mathrm{m}^{3}$ (Table 1).

\section{Seasonal variation in dioxins (PCDDs/Fs) concentration}

The temporal variations of PCDD/Fs have been examined using three daily data per month at each site (Fig. 4). The results of our analysis were comparable between sites. For example, at site N, $\Sigma$ PCDD/F values peaked in February at 2,512 (124 $\left.\mathrm{WHO}_{05} \mathrm{TEQ}\right) \mathrm{fg} / \mathrm{m}^{3}$, while they dropped dramatically to 1,205 (70 $\mathrm{WHO}_{05} \mathrm{TEQ}$ ) $\mathrm{fg} / \mathrm{m}^{3}$ in June (Fig. 4). As seen in Fig. 2S, the highest concentrations of $\Sigma \mathrm{PCDD} / \mathrm{Fs}$ were seen consistently in winter $\left(2,226 \mathrm{fg} / \mathrm{m}^{3}(\mathrm{~W})\right.$ to 3,291 $(\mathrm{S})$ ), while the lowest values occurred in summer $(1,117$ (E) to $1,532 \mathrm{fg} / \mathrm{m}^{3}$ (S) (Fig. 2S). This observation is analogous to the seasonal profile seen for PAHs, where concentrations are lower in the summer because of reduced commercial and residential fuel use for heating purposes and much higher in the winter when there is substantial fuel use (including solid fuel burning) for heating (Anthwal et al. 2010). Similar reasons most probably underpin the seasonal trends observed for dioxin concentrations. In a previous study conducted in a residential/industrial complex in Houston, Texas, US, similar seasonal patterns were also observed with enhanced PCDD/F levels in winter relative to summer (Raun et al. 2005). Such patterns were seen consistently from urban and rural sites in the Malopolski region, southern Poland (Umlauf et. al. 2010). However, these authors also found that such seasonal distinctions were no longer observed in industrial sites with similar PCDD/Fs values occurring in both summer and winter-presumably as a result of the more constant usage of fuel throughout the year by industrial facilities.

Sources of PCDD/Fs have been identified to include various man-made processes such as domestic cooking and heating, power stations, vehicle exhaust emissions, steelworks, metal refineries, municipal and medical waste incineration, and production of cement, lime, glass, and brick (Chen 2004; Cohen et al. 2002; Karasek and Hutzinger 1986). In addition to these well-known local sources, it is also difficult to exclude the role of long-range transport as an additional, minor source component, especially during spring (or winter) known as periods of low precipitation (Tysklind et al. 1993; Dyke and Stratford 2002). Lower dioxin concentrations in the summer months may be explained additionally by factors such as summertime monsoons and the development of deep mixing layers. The mean precipitation in May and June was in the range of $13.2(\mathrm{~S})-21.7 \mathrm{~mm}(\mathrm{~W})$, although there was no precipitation in February to April during the period of our measurements. The winter-time enhancement, observed consistently from all four residential sites, is likely to be explained in the most part by the combined effects of such factors as the increased domestic and commercial fuel usage for heating.

\section{Gas-particle partitioning of PCDD/Fs}

The estimated fraction of the 2,3,7,8-substituted congeners associated with the particulate phase using the models described for gas/particle partitioning of PCDD/Fs (above) is presented in Table $3 \mathrm{~S}$. In brief, the more chlorinated compounds at the four urban sites during February to May tended to be found predominately in the particulate phase (Fig. 5). In addition, 2,3,7,8-PCDD congeners tend to be found more in the particulate phase as compared to the 2,3,7,8-PCDF congeners. For instance, the particulate fractions of TCDD (and TCDF) ranged from $0.33(0.28)$ to $0.54(0.47)$ with a mean of $0.43(0.36)$ (i.e., mainly in the gas phase). The fraction of $1,2,3,7,8$ PeCDD (and PeCDFs) ranged from $0.50(0.55)$ to 0.72 (0.83) with a mean of 0.61 (about 0.70) (i.e., mainly in the particulate phase). The fractions of HxCDDs (and HxCDFs) ranged from $0.80(0.77)$ to 0.97 (0.97) with a mean of about 0.9 (i.e., predominantly in the particulate phase). The fractions of $\mathrm{HpCDD} / \mathrm{Fs}$ as well as OCDDs/Fs were in excess of 0.86 . These trends probably confirm that the lower vapor pressure of the more chlorinated compounds compared to the less chlorinated compounds (Lee and Jones 1999).

Since partitioning is largely determined by the vapor pressure of the species, which itself is strongly related to temperature, the effect of ambient temperature on the monthly variation of gas-particle partitioning for the less chlorinated compounds such as $2,3,7,8-\mathrm{TCDD} / \mathrm{Fs}$ was prominent relative to the more chlorinated compounds such as HpCDD/Fs. Eitzer and Hites (1989) reported winter particle fractions of $<0.5$ for Bloomington, Indiana, USA 
Fig. 4 Temporal variations of PCDD/Fs in air at 4 urban sites by using individual daily measurement data $(n=3$ for each month) between February and June 2009
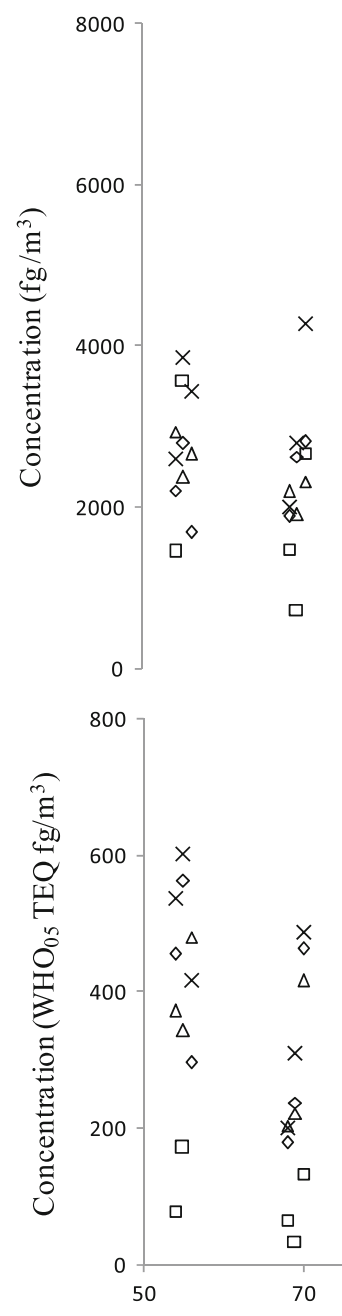

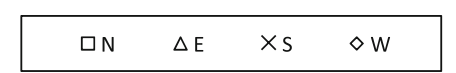

$\Delta$

$\diamond$

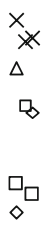

$\Delta^{\diamond}$

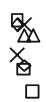

$\underset{x}{\stackrel{x}{Q}}$

$\hat{x}$

$\times$

$\diamond$

$\times$

8

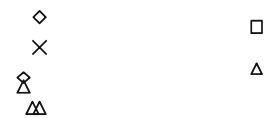

c

$\stackrel{\ddot{x}}{\dot{\square}}$

$130 \quad 150 \quad 170$

Time (Julian day)

Particle phase Gas phase

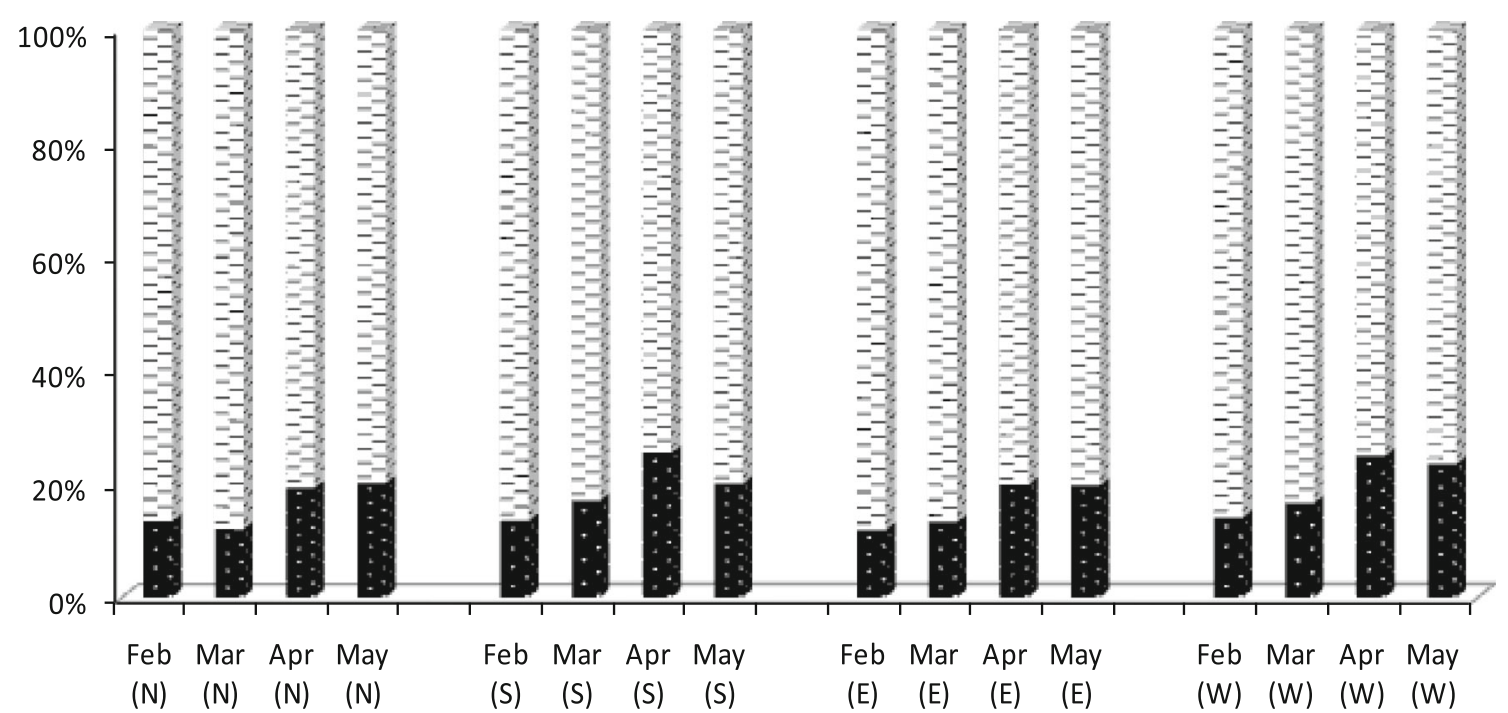

Fig. 5 Gas-particle partitioning of $\sum 2,3,7,8-\mathrm{PCDD} / \mathrm{Fs}$ across the four urban sites in Seoul 
Table 2 Results of principal component analysis (PCA) for PCDD/Fs and relevant environmental parameters at each station ${ }^{\mathrm{a}}$

\begin{tabular}{|c|c|c|c|c|c|c|c|c|c|c|c|c|}
\hline & \multicolumn{6}{|l|}{$\mathrm{N}$} & \multicolumn{6}{|l|}{ E } \\
\hline & PC1 & PC2 & PC3 & PC4 & PC5 & PC6 & PC1 & $\mathrm{PC} 2$ & PC3 & PC4 & PC5 & PC6 \\
\hline OCDD & $0.43^{\mathrm{b}}$ & -0.67 & 0.54 & -0.03 & -0.03 & -0.09 & -0.15 & 0.86 & -0.17 & 0.32 & 0.27 & 0.05 \\
\hline OCDF & 0.35 & 0.28 & 0.06 & -0.16 & 0.38 & -0.62 & 0.20 & 0.26 & 0.32 & 0.12 & 0.58 & 0.51 \\
\hline 1234678-HpCDD & 0.79 & -0.46 & 0.37 & -0.04 & -0.07 & 0.07 & 0.84 & 0.08 & 0.35 & -0.05 & -0.08 & 0.14 \\
\hline 1234789-HpCDF & 0.73 & 0.44 & -0.24 & -0.12 & 0.38 & 0.03 & 0.78 & 0.39 & 0.24 & 0.33 & -0.16 & -0.04 \\
\hline 1234678-HpCDF & 0.93 & -0.02 & 0.25 & -0.16 & 0.01 & -0.03 & 0.75 & 0.48 & 0.29 & 0.32 & -0.12 & -0.02 \\
\hline 123789-HxCDD & 0.61 & 0.00 & -0.56 & -0.05 & 0.48 & 0.05 & 0.94 & -0.05 & 0.15 & -0.10 & 0.01 & 0.03 \\
\hline 123678-HxCDD & 0.81 & -0.57 & 0.13 & 0.02 & 0.01 & -0.03 & 0.88 & -0.10 & 0.30 & -0.10 & 0.09 & 0.04 \\
\hline 123478-HxCDD & 0.67 & -0.68 & 0.21 & 0.10 & -0.12 & 0.03 & 0.92 & 0.06 & 0.07 & -0.03 & 0.08 & 0.03 \\
\hline 123789-HxCDF & 0.53 & -0.02 & -0.64 & -0.08 & 0.39 & 0.08 & 0.80 & 0.07 & -0.34 & 0.11 & -0.15 & -0.27 \\
\hline 234678-HxCDF & 0.93 & -0.23 & 0.19 & -0.13 & 0.06 & 0.08 & 0.84 & 0.37 & 0.27 & 0.27 & -0.07 & -0.04 \\
\hline 123678-HxCDF & 0.96 & -0.16 & 0.16 & -0.08 & 0.06 & 0.08 & 0.88 & 0.31 & 0.23 & 0.21 & -0.09 & 0.05 \\
\hline 123478-HxCDF & 0.94 & 0.01 & 0.21 & -0.05 & 0.14 & 0.14 & 0.88 & 0.32 & 0.21 & 0.22 & -0.09 & 0.05 \\
\hline 12378-PeCDD & 0.55 & -0.74 & 0.25 & 0.04 & -0.10 & 0.01 & 0.87 & -0.26 & -0.20 & -0.14 & 0.05 & -0.30 \\
\hline 23478-PeCDF & 0.91 & -0.29 & 0.16 & -0.02 & 0.05 & 0.12 & 0.98 & 0.07 & 0.12 & 0.10 & 0.00 & 0.01 \\
\hline 12378-PeCDF & 0.94 & -0.13 & 0.08 & 0.05 & 0.15 & 0.08 & 0.91 & -0.32 & 0.05 & -0.05 & 0.04 & 0.05 \\
\hline 2378-TCDD & 0.36 & -0.80 & 0.11 & 0.11 & -0.20 & 0.15 & 0.85 & -0.26 & 0.26 & -0.18 & -0.06 & 0.05 \\
\hline 2378-TCDF & 0.87 & -0.11 & -0.03 & 0.02 & 0.38 & -0.03 & 0.29 & -0.79 & -0.09 & -0.15 & 0.27 & 0.10 \\
\hline $\mathrm{SO}_{2}$ & 0.80 & 0.32 & 0.05 & 0.12 & -0.30 & -0.19 & -0.03 & 0.73 & -0.12 & -0.57 & -0.13 & 0.27 \\
\hline NO & 0.56 & 0.24 & -0.54 & -0.23 & -0.33 & 0.35 & 0.51 & 0.46 & -0.58 & -0.21 & 0.21 & -0.26 \\
\hline $\mathrm{NO}_{2}$ & 0.72 & 0.58 & -0.07 & -0.17 & -0.29 & -0.06 & 0.10 & 0.93 & -0.31 & -0.08 & 0.08 & -0.03 \\
\hline $\mathrm{NO}_{\mathrm{X}}$ & 0.71 & 0.48 & -0.26 & -0.21 & -0.33 & 0.10 & 0.31 & 0.78 & -0.47 & -0.16 & 0.16 & -0.14 \\
\hline $\mathrm{CO}$ & 0.81 & 0.44 & -0.20 & -0.16 & -0.24 & -0.07 & 0.19 & 0.81 & -0.48 & -0.02 & -0.16 & 0.17 \\
\hline $\mathrm{O}_{3}$ & 0.07 & 0.62 & 0.47 & 0.47 & 0.16 & -0.11 & -0.60 & 0.50 & 0.33 & -0.01 & -0.25 & 0.09 \\
\hline TSP & 0.69 & 0.61 & 0.24 & 0.26 & -0.07 & -0.08 & -0.09 & 0.94 & 0.13 & -0.25 & -0.11 & -0.07 \\
\hline $\mathrm{PM}_{10}$ & 0.73 & 0.54 & 0.17 & 0.16 & -0.19 & -0.23 & 0.01 & 0.93 & 0.02 & -0.33 & -0.11 & 0.05 \\
\hline $\mathrm{PM}_{2.5}$ & 0.74 & 0.46 & 0.09 & -0.01 & -0.11 & -0.41 & 0.02 & 0.88 & -0.09 & -0.30 & -0.22 & 0.24 \\
\hline TEMP & 0.08 & 0.51 & 0.35 & -0.73 & 0.05 & 0.17 & -0.48 & 0.47 & -0.12 & 0.69 & -0.08 & -0.11 \\
\hline HUM & -0.17 & -0.41 & 0.06 & -0.81 & 0.09 & -0.24 & -0.16 & -0.33 & -0.45 & 0.63 & -0.36 & 0.27 \\
\hline WS & -0.42 & -0.08 & 0.66 & 0.51 & 0.20 & 0.03 & -0.41 & 0.17 & 0.83 & -0.09 & -0.06 & 0.01 \\
\hline UV & -0.26 & 0.65 & 0.57 & -0.11 & 0.12 & 0.32 & -0.41 & 0.17 & 0.83 & -0.09 & -0.06 & 0.01 \\
\hline Solar & 0.02 & 0.76 & 0.46 & 0.36 & 0.04 & 0.11 & -0.46 & 0.50 & 0.60 & 0.16 & 0.09 & -0.35 \\
\hline $\mathrm{CH}_{4}$ & 0.41 & -0.17 & -0.50 & 0.73 & -0.04 & -0.06 & -0.29 & 0.64 & 0.60 & -0.14 & 0.13 & -0.30 \\
\hline $\mathrm{NCH}_{4}$ & 0.30 & 0.44 & 0.18 & 0.03 & 0.19 & 0.64 & -0.25 & 0.68 & 0.04 & 0.50 & 0.38 & 0.05 \\
\hline THC & 0.49 & -0.07 & -0.45 & 0.73 & 0.00 & 0.09 & -0.03 & 0.89 & -0.37 & 0.06 & 0.09 & 0.03 \\
\hline Eigenvalues & 14.7 & 6.94 & 3.86 & 3.27 & 1.57 & 1.53 & 12.4 & 10.36 & 4.42 & 2.48 & 1.17 & 1.03 \\
\hline$\%$ of variance & 29.1 & 23.8 & 13.0 & 12.0 & 10.8 & 5.0 & 32.5 & 25.0 & 16.7 & 11.6 & 4.35 & 3.59 \\
\hline \multirow[t]{3}{*}{ Total } & \multicolumn{5}{|c|}{93.6} & \multicolumn{7}{|c|}{93.7} \\
\hline & \multicolumn{5}{|l|}{$\mathrm{S}$} & \multicolumn{7}{|l|}{ W } \\
\hline & $\mathrm{PC} 1$ & PC2 & & C3 & PC4 & $\mathrm{PC} 1^{\mathrm{b}}$ & $\mathrm{PC} 2$ & PC3 & & PC4 & PC5 & PC6 \\
\hline OCDD & 0.40 & -0.47 & & 0.38 & -0.21 & 0.59 & -0.12 & -0.40 & & 0.24 & 0.48 & -0.10 \\
\hline OCDF & 0.66 & 0.60 & & 0.05 & -0.12 & 0.43 & 0.48 & -0.16 & & 0.57 & 0.13 & -0.11 \\
\hline 1234678-HpCDD & 0.69 & -0.53 & & 0.30 & -0.20 & 0.71 & -0.34 & 0.13 & & -0.08 & -0.29 & 0.25 \\
\hline 1234789-HpCDF & 0.90 & 0.31 & & 0.12 & -0.12 & 0.72 & -0.07 & 0.54 & & 0.32 & 0.12 & 0.03 \\
\hline 1234678-HpCDF & 0.90 & 0.24 & & 0.06 & -0.18 & 0.92 & -0.13 & 0.03 & & 0.21 & 0.20 & -0.11 \\
\hline 123789-HxCDD & 0.80 & -0.56 & & 0.08 & 0.07 & 0.80 & -0.31 & 0.36 & & -0.07 & -0.25 & 0.16 \\
\hline 123678-HxCDD & 0.82 & -0.54 & & 0.06 & 0.02 & 0.59 & 0.01 & -0.73 & & 0.21 & 0.20 & 0.05 \\
\hline 123478-HxCDD & 0.69 & -0.35 & & 0.16 & -0.43 & 0.91 & -0.29 & -0.17 & & 0.11 & -0.09 & -0.09 \\
\hline
\end{tabular}


Table 2 continued

\begin{tabular}{|c|c|c|c|c|c|c|c|c|c|c|}
\hline & \multicolumn{4}{|l|}{$S$} & \multicolumn{6}{|l|}{ W } \\
\hline & PC1 & $\mathrm{PC} 2$ & PC3 & $\mathrm{PC} 4$ & $\mathrm{PC} 1^{\mathrm{b}}$ & PC2 & PC3 & $\mathrm{PC} 4$ & PC5 & PC6 \\
\hline 123789-HxCDF & 0.67 & -0.30 & -0.01 & 0.49 & 0.66 & -0.21 & 0.63 & 0.02 & -0.18 & 0.00 \\
\hline 234678-HxCDF & 0.93 & 0.03 & 0.08 & -0.22 & 0.93 & -0.17 & 0.18 & 0.19 & 0.13 & 0.00 \\
\hline 123678-HxCDF & 0.97 & -0.06 & 0.07 & -0.16 & 0.92 & -0.14 & 0.33 & 0.14 & -0.05 & 0.04 \\
\hline 123478-HxCDF & 0.98 & -0.05 & 0.04 & -0.08 & 0.96 & -0.12 & 0.14 & 0.17 & 0.02 & 0.02 \\
\hline 12378-PeCDD & 0.83 & -0.47 & 0.02 & 0.01 & 0.57 & 0.13 & -0.59 & 0.30 & 0.38 & -0.02 \\
\hline 23478-PeCDF & 0.95 & -0.26 & 0.04 & -0.04 & 0.97 & -0.05 & 0.09 & 0.12 & -0.02 & 0.09 \\
\hline 12378-PeCDF & 0.95 & -0.24 & 0.02 & -0.05 & 0.94 & -0.04 & 0.23 & 0.07 & -0.04 & 0.12 \\
\hline 2378-TCDD & 0.60 & -0.16 & 0.25 & 0.41 & 0.37 & -0.38 & -0.75 & -0.02 & -0.28 & -0.01 \\
\hline 2378-TCDF & 0.93 & -0.34 & 0.03 & 0.06 & 0.90 & 0.11 & 0.04 & 0.20 & 0.15 & 0.17 \\
\hline $\mathrm{SO}_{2}$ & 0.67 & 0.55 & 0.22 & -0.32 & -0.22 & 0.84 & 0.11 & 0.14 & -0.28 & -0.27 \\
\hline NO & 0.75 & -0.22 & -0.39 & 0.42 & 0.62 & 0.57 & -0.30 & -0.41 & 0.03 & -0.07 \\
\hline $\mathrm{NO}_{2}$ & 0.84 & 0.39 & -0.23 & 0.18 & 0.30 & 0.91 & -0.01 & -0.04 & -0.02 & -0.22 \\
\hline $\mathrm{NO}_{\mathrm{X}}$ & 0.85 & 0.08 & -0.33 & 0.33 & 0.49 & 0.80 & -0.15 & -0.24 & 0.00 & -0.16 \\
\hline $\mathrm{CO}$ & 0.93 & 0.26 & -0.09 & 0.05 & 0.63 & 0.33 & -0.39 & 0.12 & -0.32 & -0.02 \\
\hline $\mathrm{O}_{3}$ & -0.03 & 0.80 & 0.28 & -0.38 & -0.67 & 0.26 & 0.04 & 0.61 & -0.17 & 0.19 \\
\hline TSP & 0.68 & 0.65 & 0.25 & 0.07 & 0.00 & 0.92 & 0.15 & 0.28 & -0.22 & 0.04 \\
\hline $\mathrm{PM}_{10}$ & 0.73 & 0.61 & 0.17 & -0.03 & 0.03 & 0.91 & 0.17 & 0.26 & -0.24 & -0.06 \\
\hline $\mathrm{PM}_{2.5}$ & 0.72 & 0.57 & 0.06 & -0.25 & 0.07 & 0.84 & 0.19 & 0.30 & -0.25 & -0.28 \\
\hline TEMP & -0.09 & 0.71 & -0.55 & 0.03 & -0.35 & 0.33 & 0.31 & 0.11 & 0.76 & -0.22 \\
\hline HUM & -0.49 & -0.12 & -0.60 & -0.43 & 0.08 & -0.49 & 0.38 & -0.08 & 0.39 & -0.64 \\
\hline WS & -0.35 & -0.03 & 0.87 & 0.19 & -0.52 & -0.51 & 0.04 & 0.47 & 0.01 & -0.15 \\
\hline UV & -0.35 & -0.03 & 0.87 & 0.19 & -0.61 & 0.05 & 0.16 & 0.31 & 0.58 & 0.38 \\
\hline Solar & -0.30 & 0.78 & 0.08 & 0.30 & -0.52 & 0.51 & 0.02 & 0.46 & 0.12 & 0.49 \\
\hline $\mathrm{CH}_{4}$ & 0.09 & 0.79 & 0.44 & 0.34 & 0.42 & 0.54 & 0.10 & -0.49 & 0.27 & 0.26 \\
\hline $\mathrm{NCH}_{4}$ & 0.85 & 0.26 & -0.27 & 0.17 & 0.20 & 0.66 & 0.10 & -0.42 & 0.28 & 0.12 \\
\hline THC & 0.85 & 0.20 & -0.43 & 0.10 & 0.39 & 0.62 & 0.10 & -0.52 & 0.29 & 0.22 \\
\hline Eigenvalues & 18.3 & 6.52 & 3.54 & 1.97 & 13.4 & 7.87 & 3.38 & 2.94 & 2.49 & 1.45 \\
\hline$\%$ of variance & 32.0 & 26.4 & 20.2 & 10.5 & 29.6 & 17.0 & 15.7 & 13.7 & 10.5 & 6.17 \\
\hline Total & & 89.1 & & & & & 92.7 & & & \\
\hline
\end{tabular}

${ }^{a}$ Extraction method: PCA; rotation method: varimax with Kaiser normalization

b PC: principal component loading

${ }^{c}$ Values equal to or above 0.50 are shown in bold phase

(winter temperature $<2.8{ }^{\circ} \mathrm{C}$ ). Correa et al. (2004) reported particle fraction of $<0.26$ for 2,3,7,8-TCDD/Fs in Houston, Texas, USA (temperature range of $10.5-20.9^{\circ} \mathrm{C}$ ) during February to April. Meanwhile, the vapor pressures $\left(P_{\mathrm{L}}^{0}\right)$ of 2,3,7,8-substituted congeners estimated using RTI (Eq. 4) were not significantly different from those using Eq. 2 except for 1,2,3,6,7,8-HxCDF (approximately $<70 \%$ on average), while the former were generally significantly higher than those using the vapor pressure of the crystalline solid (Eq. 3). Lohmann et al. (2000) and Correa et al. (2004) found that the $P_{\mathrm{L}}^{0}$ using RTI are more accurate than those obtained with the entropy-based method (Eq. 3). The difference in the particulate fractionation of 2,3,7,8substituted congeners resulting from the different vapor pressure calculation methods (Eqs. 2 and 4) was less than $5 \%(<80 \%$ between Eqs. 3 and 4$)$. In general, the particulate fraction estimated using RTI showed the lowest value. Although there is a significant difference in estimated partitioning coefficient $\left(K_{\mathrm{p}}\right)$ between the $\mathrm{K}_{\mathrm{oa}}$-based (Eq. 6) and $P_{\mathrm{L}}^{0}$-based (Eq. 5) methods, the resulting particulate fractionation difference is insignificant. In addition, the differences in $\mathrm{K}_{\mathrm{oa}}$ obtained from $\mathrm{K}_{\mathrm{ow}}$-based (Eq. 7), RTI-based (Eq. 8), and temperature-based (Eq. 9) methods are significant. For instance, RTI-based $\mathrm{K}_{\mathrm{oa}}$ values were significantly different from $\mathrm{K}_{\mathrm{ow}}$-based $\mathrm{K}_{\mathrm{oa}}$ values ( $>30 \%$ higher, on average). However, the calculated particulate fractionation of 2,3,7,8-substituted congeners was not highly sensitive to the $\mathrm{K}_{\mathrm{p}}$ (as well as $\mathrm{K}_{\mathrm{oa}}$ ) calculation 
methods. Oh et al. (2001) found that for the calculation of the particulate phase fraction, the $\mathrm{K}_{\mathrm{oa}}$-based method is more compatible with experimental data than $\mathrm{K}_{\mathrm{p}}$-based method. Unfortunately in this study, it was not possible to perform a direct comparison between measured and estimated $\mathrm{K}_{\mathrm{p}}$ (particle + gas phase concentration) due to the limitations of the measurement campaign.

\section{Factors affecting the environmental behavior of PCDD/Fs}

To understand the basic factors and processes controlling the distribution of PCDD/Fs at all four sites, principal component analysis (PCA) was conducted by using the measured concentrations at each site, other commonly measured pollutants, and meteorological parameters. As part of factor analysis (FA), PCA is based on a numerical approach to account for the statistical variance of the data by producing a small number of output factors which encompass the majority of the dataset from a large number of input variables (Garson 1998).

In this study, the principal components with eigenvalues in excess of 1 were used in our interpretation of PCDD/F behavior (Table 2). Based on this approach, six major components were identified at three sites (N, E, and W). In contrast, four major groups were identified at site $\mathrm{S}$. According to this PCA, the total variance described by these major components varied across the 4 sites in the range of $89.4 \%(\mathrm{~S})$ to $93.7 \%$ (E) (Table 2). The first component was generally dominated by most PCDD/Fs along with other common pollutant types $\left(\mathrm{SO}_{2}, \mathrm{NO}, \mathrm{NO}_{\mathrm{X}}, \mathrm{CO}, \mathrm{TSP}, \mathrm{PM}_{2.5}, \mathrm{PM}_{10}\right.$, and THC), accounting for $29.1,32.5,18.3$, and $29.6 \%$ of total variance in $\mathrm{N}, \mathrm{E}, \mathrm{S}$, and $\mathrm{W}$ sites, respectively. The smaller projection onto the first variable for site $\mathrm{S}$ indicates a mixture of sources at this location. Pollutants such as NOx, $\mathrm{PM}_{10}$, $\mathrm{PM}_{2.5}, \mathrm{CO}$, and THC are known to be released from vehicular emissions along with coal (or gas) burning. Hence, this component is most likely to represent source activities such as traffic and heating processes (by natural gas). Except for site $\mathrm{E}$, the second component was generally dominated by very high loadings of some other gaseous pollutants. The PCA analysis, where the concentration from site $\mathrm{S}$ was less strongly correlated than at other sites, taken together with the findings of enhanced PCDD/Fs levels at site $\mathrm{S}$ relative other sites, suggests that the source processes at site $\mathrm{S}$ are significantly different from those impinging on the other sites and are probably more variable in nature.

\section{Conclusion}

In order to assess the level of PCDD/Fs pollution from four urban residential locations in Seoul, air samples were collected over three consecutive days per month from
February to June 2009. The results of our study have been analyzed to derive the present status of PCDD/Fs pollution in urban residential areas in Seoul, Korea. The $\Sigma$ PCCDD/ Fs concentrations measured from four sites averaged 2,125 (292 $\left.\mathrm{WHO}_{05} \mathrm{TEQ}\right) \mathrm{fg} / \mathrm{m}^{3}$, while relative contributions from $\Sigma$ PCDDs and $\Sigma$ PCDFs were significantly different at 527 (30 $\mathrm{WHO}_{05}$ TEQ) and 1,598 (263 $\mathrm{WHO}_{05}$ TEQ) fg/ $\mathrm{m}^{3}$, respectively. When compared to other data in the literature, this suggests decreasing concentrations of dioxins in the ambient air of Seoul over the last decade, presumably as a function of increased controls on airborne emissions over these periods. Comparison of the data across the four sites suggests that sources affecting site $S$ (which generally showed the highest concentrations) are likely to be different from and more variable than those impinging on the other three sites. The analysis of seasonal patterns indicated a strong trend in which relative enhancement of PCDD/Fs was seen in the winter and spring months, regardless of study site. This is a very similar conclusion to those drawn from similar studies of PAH concentrations in cities where there is a significant source component of fuel burning for residential and commercial heating (Brown and Brown 2012), and indeed, the dioxins are expected to originate from similar sources. In addition, it was found that chlorinated compounds at the four urban sites during February to May were found preferentially in the particulate phase. Furthermore, 2,3,7,8-PCDD congeners tend to be found more in the particle phase than the $2,3,7,8-\mathrm{PCDF}$ congeners.

Acknowledgments This study was supported by a National Research Foundation of Korea (NRF) grant funded by the Ministry of Education, Science and Technology (MEST) (No. 2009-0093848). The ninth author acknowledges the support made by a grant from the Korea Basic Science Institute (project No. T31603). We also acknowledge partial support made by the Human Resources Development of the Korea Institute of Energy Technology Evaluation and Planning (KETEP) grant funded by the Korea government Ministry of Knowledge Economy (No. 20094010200030).

\section{References}

Anthwal A, Jung K, Kim HJ, Bae IIS, Kim K-H (2010) Polycyclic aromatic hydrocarbons in ambient air at four urban locations of Seoul Korea. Fresen Environ Bull 19(7):1356-1368

ATSDR (1998) Agency for Toxic Substances and Disease Registry. Toxicological profile for chlorinated dibenzo-p-dioxins (CDDs). Atlanta, GA: US Department of Health and Human Services, Public Health;. Service. http://www.atsdr.cdc.gov/toxprofiles/tp. asp? $\mathrm{id}=366 \&$ tid $=63$

Atkinson R (1996) Atmospheric chemistry of PCBs, PCDDs and PCDFs. In: Chlorinated organic micropollutants. In: Issues in Environmental Sciences and Technology, vol 6. The Royal Society of Chemistry

Bao L, Sakamoto K (2009) Chemical characterization of watersoluble organic acids in size-segregated particles at a suburban site in Saitama, Japan. Asian J Atmos Environ 3:42-51 
Bocio A, Domingo JL (2005) Daily intake of polychlorinated dibenzo-p-dioxins/polychlorinated dibenzofurans (PCDD/ PCDFs) in foodstuffs consumed in Tarragona, Spain: a review of recent studies (2001-2003) on human PCDD/PCDF exposure through the diet. Environ Res 97:1-9

Chen CM (2004) The emission inventory of PCDD/PCDF in Taiwan. Chemosphere 54(10):1413-1420

Cohen MD, Draxler RR, Artz R (2002) Modeling the atmospheric transport and deposition of PCDD/F to the Great Lakes. Environ Sci Technol 36:4831-4845

Cleverly DH, Winters D, Ferrario J, Schaum J, Schweer G, Buchert J, Greene C, Dupuy A, Byrne C (2000) The national dioxin air monitoring network (NDAMN): results of the first year of atmospheric measurements of CDDs, CDFs and dioxin-like PCBs in rural and agricultural areas of the United States: June 1998-June 1999. Organohalogen Compd 45:248-251

Climatemap Seoul (2013). Available at: http://www.seoul.climatemps. $\mathrm{com} /$

Correa O, Rifai H, Raun L, Suarez M, Koenig L (2004) Concentrations and vapor-particle partitioning of polychlorinated dibenzo$p$-dioxins and dibenzofurans in ambient air of Houston, Tx. Atmos Environ 38:6687-6699

De Assunc, ao JV, Pesquero CR, Bruns RE, Carvalho LRF (2005) Dioxins and furans in the atmosphere of São Paulo City, Brazil. Chemosphere 58:1391-1398

de Wit (2002) An overview of brominated flame retardants in the environment. Chemosphere 46:583-624

Donelly JR, Munslow WD, Mitchum RK, Sovocool GW (1987) Correlation of structure with retention index for chlorinated dibenzo-p-dioxins. J Chromatogr 392:51-63

Dyke PH, Stratford J (2002) Changes to the TEF schemes can have significant impacts on regulation and management of $\mathrm{PCDD} / \mathrm{F}$ and PCB. Chemosphere 47:103-116

Eitzer BD, Hites RA (1988) Vapor pressures of chlorinated dioxins and dibenzofurans. Environ Sci Technol 22:1362-1364

Eitzer BD, Hites RA (1989) Polychlorinated dibenzo-p-dioxins and dibenzofurans in the ambient atmosphere of Bloomington, Indiana. Environ Sci Technol 23:1389-1395

Fiedler H (2003) Dioxins and furans (PCDD/PCDF) In: H. Fiedler (Ed.), Persistent organic pollutants, the handbook of environmental chemistry. Anthropogenic compounds, Part O, vol. 3, Springer, Berlin: 123-201 Heidelberg

Garson GD (1998) Factor analysis. Available at-http://faculty.chass. ncsu.edu/garson/PA765/factor.htm (retrieved July 20, 2011)

Gras J, Muller J (2004) Dioxins in ambient air in Australiatechnical report no 4. Appendix F Summary of published dioxins concentrations, Department of the Environment and Heritage, Australian Government

Govers HAJ, Krop HB (1998) Partition constants of chlorinated dibenzofurans and dibenzo-p-dioxins. Chemosphere $37: 2139-2152$

Hale MD, Hileman FD, Mazer T, Shell TL, Noble RW, Brooks JJ (1985) Mathematical modeling of temperature programme capillary gas chromatographic retention indexes for chlorinated dibenzofurans. Anal Chem 57:640-648

Harner T, Bidleman TF (1998) Octanol-air partition coefficient for describing particle/gas partitioning of aromatic compounds in urban air. Environ Sci Technol 32:1494-1502

Harner T, Green NJL, Jones KC (2000) Measurements of octanol-air partition coefficients for PCDD/Fs: a tool in assessing air-soil equilibrium status. Environ Sci Technol 34:3109-3114

Hinckley DA, Bidleman TF, Foreman WT, Tushall JR (1990) Determination of vapor pressures for nonpolar and semipolar organic compounds from gas chromatographic retention data. J Chem Eng Data 35:232-237
Huang Z, Tonooka V, Sekiguchi K, Wang Q, Sakamoto K (2009) Long-term sulfur emissions and environmental Kuznets curves: comparison and implications. Asian J Atmos Environ 3:19-26

Jin J, Li LJ, Jiang K (1995) Toxicity of polychlorinated dibenzo-pdioxins and polychlorinated dibenzofurans (PCDD/Fs) and dioxin-like compounds. Shanghai Environ Sci 14:29-42

Junge CE (1977) Basic consideration about trace constituents in the atmosphere as related to the facte of global pollutants. In: Suffet $\mathrm{IH}$ (ed) Fate of pollutants in the air and water environments. Wiley, New York, pp 7-25

Karasek FW, Hutzinger O (1986) Report: incineration, dioxin formation. Anal Chem 58:633-640

Kim K-H, Jo S-H, Song H-C, Pandey SK, Song H-N, Oh J-M, Sunwoo Y, Choi KC (2013) Diagnostic analysis of offensive odorants in a large municipal waste treatment plant in an urban area. Int J Environ Sci Tech 10(2):261-274

Kim M-Y, Choi YS, Bae IS, Yoon JS, Eom SW (2010) SpatioTemporal concentration profiles and variations of polychlorinated dibenzo-p-dioxins (PCDDs) and dibenzofurans (PCDFs) in ambient air of Seoul, Korea. 15th IUAPPA World Clean Air Congress. http://events.awma.org/IUAPPA/presentations/Wed\% 20Posters/a114_1.pdf

Kim BH, Lee SJ, Mun SJ, Chang YS (2005) A case study of dioxin monitoring in and around an industrial waste incinerator in Korea. Chemosphere 58:1589-1599

Kim SC, Jeon SH, Jung IR, Kim KH, Kwon MH, Kim JH, Yi JH, Kim SJ, You JC, Jung DH (2001a) Formation and emission status of PCDDs/PCDFs in municipal solid waste incinerators in Korea. Chemosphere 43:701-707

Kim Y, Lee SY, Kim M, Kim SD (2001b) The survey of PCDDs and PCDFs in the ambient air of the urban and industrial sites in Korea, 1998-99. Chemosphere 43:501-506

Kutz FW, Barnes DG, Bretthauer EW, Bottimore DP, Greim H (1990) The international toxicity equivalency factor (I-TEF) method for estimating risks associated with exposures to complex mixtures of dioxins and related compounds. Chemosphere 20:751-757

Lee RG, Jones KC (1999) Gas-particle partitioning of atmospheric PCDD/Fs: measurements and observations on modeling. Environ Sci Technol 33:3596-3604

Li Y, Jiang G, Wang Y, Cai Z, Zhang Q (2008) Concentrations, profiles and gas-particle partitioning of polychlorinated dibenzop-dioxins and dibenzofurans in the ambient air of Beijing, China. Atmos Environ 42:2037-2047

Lohmann R, Jones KC (1998) Dioxins and furans in air and deposition: a review of levels, behaviour and processes. Sci Total Environ 219:53-81

Lohmann R, Green NJL, Jones KC (1999) Detailed studies of the factors controlling atmospheric PCDD/F concentrations. Environ Sci Technol 33:4440-4447

Lohmann R, Lee RGM, Green NJL, Jones KC (2000) Gas-particle partitioning of $\mathrm{PCDD} / \mathrm{Fs}$ in daily air samples. Atmos Environ 34:2529-2537

Mackay D, Bobra A, Chan DW, Shiu WY (1982) Vapor pressure correlations for low-volatility environmental chemicals. Environ Sci Technol 16:645-649

Matsumoto J, Narukawa M, Takahashi K, Matsumi V, Yabushita A, Shimizu A, Matsui I, Sugimoto N (2009) Internal mixing of pollutants for submicron particles observed during springtime in Japan. Asian J Atmos Environ 3:27-41

Oh JE, Choi SK, Lee SJ, Chang YS (2006) Influence of a municipal solid waste incinerator on ambient air and soil PCDD/Fs levels. Chemosphere 64:579-587

Oh JE, Choi JS, Chang YS (2001) Gas/particle partitioning of polychlorinated dibenzo-p-dioxins and dibenzofurans in atmosphere; evaluation of predicting models. Atmos Environ 35:4125-4134 
Paasivirta J, Sinkkonen S, Mikkelson P, Rantio T, Wania F (1999) Estimation of vapor pressures, solubilities and Henry's low constants of selected persistent organic pollutants as functions of temperature. Chemosphere 39:811-832

Pankow JF (1987) Review and comparative analysis of the theories on partitioning between the gas and aerosol particulate phases in the atmosphere. Atmos Environ 21:2275-2283

Pankow JF (1991) Common y-intercept and single compound regression of gas-particle partitioning data. Atmos Environ 25A:2229-2239

Raun LH, Correa O, Rifai H, Monica S, Koenig L (2005) Statistical investigation of polychlorinated dibenzo-p-dioxins and dibenzofurans in the ambient air of Houston, Texas. Chemosphere 60:973-989

Rordorf BF (1989) Prediction of vapor pressures, boiling points and enthalpies of fusion for twenty-nine halogenated dibenzo-pdioxins and fifty-five dibenzofurans by a vapor pressure correlation method. Chemosphere 18:783-789

Seoul Metropolitan Government: Area statistics, (2010) available at http://stat.seoul.go.kr/Seoul_System5.jsp?stc_cd=412 (last retrieved 21th July, 2011)

Seinfeld JH, Pandis SN (2006) Atmospheric chemistry and physics: from air pollution to climate change, 2nd edn. Wiley, New York
Tang N, Araki Y, Tamura K, Dong L, Zhang X, Liu Q, Ji R, Kameda T, Toriba A, Hayakawa K (2009) Distribution and source of atmospheric polycyclic aromatic hydrocarbons and nitropolycyclic aromatic hydrocarbons in Tieling City, Liaoning Province, a typical local city in Northeast China. Asian J Atmos Environ 3:52-58

Tysklind M, Fangmark I, Marklund S, Lindskog A, Thaning L, Rappe C (1993) Atmospheric transport and transformation of polychlorinated dibenzo-p-dioxins and dibenzofurans. Environ Sci Technol 27:2190-2197

Umlauf G, Christoph EH, Eisenreich SJ, Mariani G, Paradiz B, Vives I (2010) Seasonality of PCDD/Fs in the ambient air of Malopolaka Region, southern Poland. Environ Sci Pollut Res 17:462-469

US EPA 1994. Method 1613: Tetra- through Octa-Chlorinated Dioxins and Furans by Isotope Dilution HRGC/HRMS. Available in- http://water.epa.gov/scitech/methods/cwa/organics/dioxins/ upload/2007_07_10_methods_method_dioxins_1613.pdf

Yamasaki H, Kuwata K, Miuamoto H (1982) Effects of ambient temperature on aspects of airborne polycyclic aromatic hydrocarbons. Environ Sci Technol 16:189-194 